$\begin{array}{ll}\text { Received } & : \text { 18 June } 2019 \\ \text { Revised } & : \text { 19 June } 2019 \\ \text { Accepted } & : \text { 28 June } 2019 \\ \text { Published } & : \text { 30 June } 2019\end{array}$

\title{
The Myth of Sandekala in Novel Senjakala by Risa Saraswati Based on Lévi-Strauss' Structuralism Approach
}

\author{
Saidah $^{1, a)}$ \\ MAN 1 Jakarta, Jakarta, Indonesia \\ E-mail: ${ }^{a}$ idasaidah919@gmail.com
}

\begin{abstract}
This study was aimed to obtain information about the sandekala myth contained in Senjakala by Risa Saraswati. The method used in this research was descriptive qualitative method. The geographical level analysis results showed that the depiction of the location of the myth in the Senjakala often linked to something haunted and mystical. Something that is haunted and mystical refers to the disturbance of spirits that often appeared when the sunset. The techno-economic level analysis results showed that the economic depiction of the figures could influence the character's behavior in believing in myths. The sociology level analysis results showed that people who own the myth have a high religious personality characterized by religion has always being used as a basis in various aspects of life, including in avoiding interference from spirits. The cosmological level analysis results showed that the events of the figures who were often disturbed by spirits during sunset. Based on these four levels, the myth of sandekala in Senjakala by Risa Saraswati was shown by the disturbances of spirits that often appeared during sunset. This research can be implicated in the study of literature at high school grade $12^{\text {th }}$ of Curriculum 2013 Revision 2018 contained in BC 3.9 Analyzing the content and linguistic elements of novels and 4.9 Designing novels or novelets with regards to the content and linguistics both verbally and written. Students are expected to be able to analyze the content and linguistic elements of the novel through intrinsic elements and the language style of the novel and having wisdom in addressing the existence of myths.
\end{abstract}

Keywords: myth of sandekala, Lévi-Strauss' structuralism, Senjakala by Risa Saraswati

\begin{abstract}
Abstrak
Penelitian ini bertujuan untuk memperoleh informasi tentang mitos sandekala yang terdapat dalam novel Senjakala karangan Risa Saraswati. Metode yang digunakan dalam penelitian ini ialah metode deskriptif kualitatif. Hasil analisis tataran geografis
\end{abstract}


menunjukkan penggambaran lokasi mitos dalam novel Senjakala kerap kali dilekatkan dengan sesuatu yang angker dan mistis. Sesuatu yang angker dan mistis tersebut merujuk pada gangguan makhluk halus yang kerap kali muncul pada waktu matahari terbenam. Hasil analisis tataran techno-economic menunjukkan penggambaran ekonomi para tokoh dapat memengaruhi sikap tokoh dalam memercayai mitos. Hasil analisis tataran sosiologi menunjukkan masyarakat pemilik mitos memiliki sifat religius tinggi yang ditandai dengan agama yang selalu dijadikan dasar dalam berbagai aspek kehidupan, termasuk dalam menghindarkan diri dari gangguan makhluk halus (Suhita \& Purwahida, 2018). Hasil analisis tataran kosmologis menunjukkan peristiwa para tokoh yang kerap kali diganggu oleh makhluk halus pada waktu terbenamnya matahari. Berdasarkan keempat tataran tersebut, mitos Sandekala dalam novel Senjakala karangan Risa Saraswati ditunjukkan dengan adanya gangguan-gangguan dari makhluk halus yang kerap kali muncul pada waktu matahari terbenam. Penelitian ini dapat diimplikasikan pada pembelajaran sastra di Sekolah Menengah Atas (SMA) kelas XII Kurikulum 2013 Revisi 2018 yang termuat dalam KD 3.9 Menganalisis isi dan kebahasaan novel dan 4.9 Merancang novel atau novelet dengan memerhatikan isi dan kebahasaan baik secara lisan maupun tulis. Siswa diharapkan mampu menganalisis isi dan kebahasaan novel melalui unsur intrinsik dan gaya bahasa novel serta memiliki kearifan dalam menyikapi keberadaan mitos.

Kata Kunci: mitos sandekala, strukturalisme Lévi-Strauss, novel Senjakala karangan Risa Saraswati

\section{PENDAHULUAN}

Indonesia merupakan negara majemuk yang memiliki keragaman baik dari segi bahasa, suku bangsa, agama, sampai dengan aliran kepercayaan. Dilihat dari luas wilayahnya, Indonesia dijuluki sebagai negara kepulauan terbesar di dunia. Adapun jumlah pulau yang dimiliki ialah sebanyak 17.504 pulau. Pulau-pulau tersebut tersebar di 34 provinsi. Berkat keragaman dan keluasan wilayah inilah yang kemudian menjadikan Indonesia sebagai negara yang kaya akan budaya dan tradisi. Keanekaragaman tradisi dan budaya tersebut dapat terlihat dari peninggalanpeninggalan nenek moyang bangsa Indonesia, salah satunya berupa karya sastra lisan (Yuliyanti, 2017; Purwahida, 2017). Sastra lisan tradisional yang sampai saat ini masih digemari, bahkan tetap diyakini, adalah mitos. Mitos merupakan sastra lisan yang mengacu kepada cerita dalam suatu kebudayaan masyarakat tertentu yang dianggap benar-benar terjadi. Dalam mitos terekam cara pandang, kepercayaan, dan perilaku masyarakat pemilik mitos. Mitos sebagai sastra lisan hadir sebelum tradisi tulis-menulis berkembang. Oleh sebab itu, mitos disebarkan secara turun-temurun melalui lisan. Mitos sebagai salah satu kekayaan budaya Indonesia selalu mengalami enkulturasi (pembinaan atau pewarisan budaya). Namun, belakangan ini tanpa ada enkulturasi pun, mitos dengan sendirinya sudah dapat membuktikan eksistensinya.

Era digital rupanya telah mengantarkan mitos sebagai salah satu kekayaan budaya yang masih eksis hingga saat ini. Hal tersebut dapat dilihat dengan maraknya YouTuber Indonesia yang menyajikan konten-konten mistis dalam saluran YouTube-nya. Kisah Tanah Jawa, Jurnalrisa, Filo Sebastian, dan Sara Wijayanto merupakan YouTuber yang membahas mengenai mitos di salurannya. Ratusan, bahkan jutaan orang telah menonton saluran YouTube mereka. Fakta tersebut membuktikan bahwa mitos sebagai salah satu 
kekayaan budaya Indonesia masih cukup eksis di era modern ini, khususnya di kalangan anak muda yang memang sangat menggemari YouTube. Namun, yang perlu digarisbawahi ialah cara menyikapi mitos itu sendiri. Maksudnya, pengetahuan tentang mitos sebagai sesuatu yang dimaksudkan kepada kekayaan budaya itu yang perlu dihadirkan dalam pembelajaran. Salah satu alternatif membelajarkan mitos ialah melalui karya sastra.

Risa Saraswati melalui karya-karyanya yang khas dan ikonik dapat menjadi alternatif dalam membelajarkan mitos itu sendiri. Salah satu karya Risa Saraswati yang dapat menjadi alternatif membelajarkan mitos ialah novel Senjakala. Novel Senjakala karangan Risa Saraswati merupakan novel yang berisi cerita tentang kepercayaan masyarakat Sunda terhadap mitos sandekala. Dalam novel diceritakan tentang tokoh Risa yang mampu melihat kejadian tak kasat mata sehingga ia mampu mengetahui halhal mistis yang terjadi ketika sandekala berlangsung. Kejadian tersebut kemudian ia ceritakan kepada teman-temannya yaitu Petter, William, Hans, Hendrick, dan Jansen. Berdasarkan pemaparan tersebut, dapat diketahui bahwa novel Senjakala karangan Risa Saraswati merupakan novel yang kaya akan mitos. Anggapan tersebut didasarkan pada cerita tentang mitos sandekala yang diangkat sebagai cerita utama dalam novel ini.

Salah satu pendekatan yang dapat digunakan untuk menganalisis mitos dalam karya sastra ialah pendekatan strukturalisme Lévi-Strauss. Hal ini didasarkan pada pendapat Jamaluddin (2013) yang mengatakan bahwa analisis strukturalisme LéviStrauss sesungguhnya berpijak pada relasi-relasi karya sastra dengan sosial-budaya. Sosial-budaya dalam konteks ini mengacu pada mitos. Adapun strukturalisme yang dimaksud oleh Lévi-Strauss tidak sama dengan strukturalisme yang selama ini dikenal dalam dunia sastra. Pendekatan strukturalisme Lévi-Strauss ialah pendekatan yang menggunakan model-model dari lingusitik untuk mengungkap fenomena suatu budaya. Selain itu, pendapat lain juga dikemukakan oleh Ahimsa-Putra (2012) yang mengatakan bahwa pendekatan strukturalisme Lévi-Strauss dapat juga diterapkan dalam menganalisis karya sastra. Berdasarkan pendapat tersebut, dapat disimpulkan bahwa pendekatan strukturalisme Lévi-Strauss dapat juga diterapkan dalam menganalisis karya sastra, khususnya karya sastra modern. Lévi-Strauss mengkaji mitos menggunakan strukturalismenya dengan cara menemukan makna dan struktur dari nalar masyarakat pemilik mitos. Sementara dalam penelitian ini, hendak menggunakan teori tataran yang dikemukakan oleh Lévi-Strauss untuk memperlihatkan mitos yang ada dalam karya sastra modern yang dalam hal ini ialah novel Senjakala karangan Risa Saraswati.

Lévi-Strauss dalam Ahimsa-Putra (2012) mengemukakan bahwa mitos tak lain ialah dongeng. Selanjutnya Haviland (1993) memberikan batasan yang berbeda mengenai mitos. Menurutnya, mitos pada dasarnya bersifat religius karena memberi rasio pada kepercayaan dan praktik keagamaan. Masalah yang dibicarakannya adalah masalah-masalah pokok kehidupan manusia: dari mana asal kita dan segala sesuatu yang ada di dunia ini, mengapa kita di sini, dan ke mana tujuan kita. Setiap aspek masalah-masalah yang sangat luas itu dapat disebut mitos. Peursen (1988) memberikan pendapat yang tak jauh berbeda dengan pendapat Haviland. Menurutnya, mitos ialah sebuah cerita yang memberikan pedoman dan arah tertentu kepada sekelompok orang. Afsari, Septiani, dan Rismamelati (2017) mengatakan bahwa sandekala merupakan pergantian waktu dari terang menuju gelap. Pada waktu tersebut merupakan waktu keluarnya makhluk halus atau dedemit yang tidak pernah muncul di waktu terang. Sandekala bagi masyarakat Sunda berfungsi sebagai larangan yang biasanya ditujukkan kepada anak-anak agar tidak bermain pada waktu matahari terbenam. Hal ini seperti 
yang dipaparkan Mustapa (2010), selain tabu, ada lagi larangan-larangan yang lain, seperti tidak boleh bermain pada waktu matahari terbenam, kalau-kalau diganggu setan. Larangan bermain pada saat senjakala berlangsung erat kaitannya dengan agama yang dianut oleh masyarakat Sunda. Masyarakat Sunda yang mayoritas beragama Islam memiliki waktu ibadah pada saat magrib atau waktu pada saat matahari terbenam. Bagi penganut agama Islam, senjakala adalah waktu yang seharusnya digunakan untuk beribadah kepada Tuhan. Dengan demikian dapat disimpulkan mitos sandekala adalah cerita atau peristiwa keluarnya makhluk halus atau setan pada waktu matahari terbenam. Mitos sandekala memiliki dua fungsi. Pertama, sebagai larangan yang umumnya ditujukan kepada anak-anak agar tidak bermain pada saat matahari terbenam. Kedua, berfungsi sebagai perintah untuk melaksanakan peribadahan.

Lévi-Strauss dalam Ahimsa-Putra (2012) menganalisis mitos dengan membedakan empat tataran yang terdapat pada mitos, yaitu (1) tataran geografis, (2) tataran technoeconomic, (3) tataran sosiologis, dan (4) tataran kosmologis.

\section{METODE PENELITIAN}

Penelitian ini merupakan penelitian deskriptif kualitatif dengan menganalisis isi karya sastra yang dibantu dengan tabel analisis data. Oleh karena itu, instrumen dalam penelitian ini ialah peneliti itu sendiri yang dibantu oleh tabel analisis data. Data yang sudah diklasifikasikan ke tabel analisis kemudian diuji keabsahannya menggunakan teknik triangulasi. Adapun teknik triangulasi yang digunakan ialah triangulasi antarpeneliti. Triangulasi antarpeneliti adalah teknik yang dilakukan dengan cara menggunakan lebih dari satu orang dalam pengumpulan dan analisis data. Adapun antarpeneliti dalam hal ini ialah peneliti bersama dua dosen pembimbing. Teknik ini telah diakui memperkaya khasanah pengetahuan yang digali dari subjek penelitian. Selain itu, melalui teknik ini, data yang diperoleh dapat terhindar dari bias yang terjadi saat pengumpulan dan analisis data.

Ruang lingkup dalam penelitian ini ialah novel Senjakala karangan Risa Saraswati. Novel tersebut diterbitkan oleh penerbit Bukune Kreatif Cipta pada tahun 2018 di Jakarta. Novel tersebut memiliki jumlah halaman sebanyak 218 halaman dengan ukuran $14 \times 20 \mathrm{~cm}$. Novel Senjakala terdiri atas sepuluh bab. Adapun pendekatan yang digunakan dalam penelitian in ialah pendekatan strukturalisme Lévi-Strauss dengan penelitian difokuskan pada mitos sandakela yang terdapat dalam novel Senjakala karangan Risa Saraswati. Subfokus dalam penelitian ini meliputi empat tataran, yaitu (1) tataran geografis, (2) tataran techno-economic, (3) tataran sosiologis, dan (4) tataran kosmologis.

\section{HASIL DAN PEMBAHASAN}

Berikut pembahasan dari hasil analisis mitos sandekala yang terdapat dalam novel Senjakala karangan Risa Saraswati berdasarkan pendekatan strukturalisme Lévi-Strauss. Berdasarkan teori strukturalisme Lévi-Strauss, mitos sandekala yang terdapat dalam novel Senjakala karangan Risa Saraswati dapat dianalisis menggunakan empat tataran yang dikemukakan oleh Lévi-Strauss. Adapun keempat tataran tersebut meliputi tataran geografis, tataran techno-economic, tataran sosiologis, dan tataran kosmologis. 


\section{Tataran Geografis}

Tataran geografis adalah tataran yang berkaitan dengan lokasi terjadinya mitos yang merujuk pada letak-letak desa atau tempat yang dijadikan latar cerita. Dalam novel Senjakala karangan Risa Saraswati, tempat atau lokasi terjadinya mitos tidak disebutkan secara rinci. Tempat atau lokasi dalam novel Senjakala karangan Risa Saraswati hanya disebutkan secara umum, seperti di depan sebatang pohon tua yang menjulang tinggi, di sekolah dan sebagainya. Selain itu, novel Senjakala merupakan novel dengan cerita berbingkai. Oleh karena itu, lokasi-lokasi yang termasuk ke dalam tataran geografis tidak merujuk pada satu tempat tertentu. Berikut akan dibahas tataran geografis mitos sandekala yang terdapat dalam novel Senjakala karangan Risa Saraswati.

Dewi Kunti kerap mengambil giliran kerja malam di rumah sakit. Sebenernya menurut rumor yang beredar, rumah sakit ini angker, tetapi baginya uang lebih penting daripada memikirkan keangkeran rumah sakit itu, yang belum jelas kebenarannya. (hlm. 91)

Pada kutipan di atas terdapat tataran geografis yang menunjukkan lokasi mitos terjadi yaitu di rumah sakit. Kata angker yang menerangkan kondisi rumah sakit menjadi mitos yang dipercayai oleh seluruh pegawai rumah sakit. Banyak dari mereka yang enggan mengambil giliran kerja pada malam hari. Kutipan lain yang juga menunjukkan adanya tataran geografis disajikan sebagai berikut.

Cempaka, daerah perbukitan itu? Jam segini? Ah sudahlah. Yang penting halal dan menghasilkan uang. (hlm. 118)

Akhirnya, kami berdua larut dalam obrolan seru. Perempuan itu berasal dari kota lain, dan berencana membeli rumah di daerah Cempaka. Sebuah daerah pinggiran kota di antara perbukitan. Tempat itu agak seram, terkenal angker dan mistis. (hlm. 121)

Berdasarkan kutipan tersebut, terdapat kutipan yang menunjukkan lokasi mitos terjadi, yaitu di daerah perbukitan bernama Cempaka. Nama daerah dalam kutipan tersebut juga dilekatkan dengan angker dan mistis. Hal tersebut yang kemudian menjadi mitos yang dipercayai. Tokoh Agus yang berprofesi sebagai supir taksi mendapat penumpang yang meminta untuk diantar ke daerah Cempaka. Tokoh Agus merasa heran karena, dengan keangkerannya yang amat terkenal, penumpangnya malah meminta diantar pada saat magrib tiba. Akan tetapi, dia tak mau ambil pusing. Baginya yang penting halal dan menghasilkan.

\section{Tataran Techno-Economic}

Tataran techno-economic merupakan tataran yang merujuk pada kehidupan ekonomi masyarakat pemilik mitos. Adapun yang termasuk ke dalam tataran technoeconomic salah satunya adalah mata pencaharian masyarakat pemilik mitos. Berikut merupakan dibahas mengenai tataran techno-economic dalam mitos sandekala yang terdapat pada novel Senjakala karangan Risa Saraswati. 
Namanya Dewi Kunti. Dia seorang suster yang bekerja di sebuah rumah sakit, membanting tulang siang-malam untuk menafkahi suaminya yang pengangguran, dan anaknya yang masih duduk di bangku SMA. (hlm. 89)

Dewi Kunti kerap mengambil giliran kerja malam di rumah sakit. Sebenarnya menurut rumor yang beredar, rumah sakit ini angker, tapi baginya uang lebih penting daripada memikirkan keangkeran rumah sakit itu, yang belum jelas kebenarannya. (Senjakala, hlm. 91)

Kata suster yang terdapat dalam kutipan tersebut termasuk ke dalam tataran techno-economic yang merujuk pada mata pencaharian masyarakat pemilik mitos. Tokoh Dewi merupakan seorang suster yang bekerja keras demi menghidupi suaminya yang pengangguran serta membiayai anaknya yang masih sekolah. Selain itu, dalam kutipan tersebut tergambar kehidupan ekonomi tokoh yang memengaruhi sikap tokoh dalam memercayai mitos. Profesi suster yang merujuk pada ekonomi kelas atas memengaruhi pola pikir Dewi Kunti. Dewi Kunti digambarkan sebagai tokoh yang logis yang tidak memercayai hal-hal yang tidak dapat dibuktikan kebenarannya. Selain perawat, dalam novel digambarkan juga profesi lain yang termasuk ke dalam mata pencaharian masyarakat pemilik mitos. Adapun kutipan yang menunjukkan hal tersebut disajikan sebagai berikut.

Toko yang dibangun oleh keluarga besarnya ini agak berbeda, karena toko ini menjual peti mati dan jasa rias jenazah. Sudah beberapa generasi keluarganya menjalin bisnis ini. Mungkin karena jarang diminati orang lain, bisa dibilang keluarga ini adalah satu-satunya yang berbisnis demikian di kota kecil ini. (hlm. 180)

Namun, Melisa bukan orang yang mudah percaya hal-hal mistis. Baginya, Jenazah hanyalah seonggok benda mati layaknya boneka. Anak itu sangat realistis, tak percaya pada hal-hal misterius yang dia anggap hanyalah sebuah omong kosong belaka. (Senjakala, hlm. 181)

Pada kutipan tersebut, digambarkan tokoh Melisa beserta keluarganya menjual peti mati dan jasa merias jenazah. Dalam kutipan tersebut tergambar mata pencaharian tokoh sebagai pedagang yang merujuk pada keadaan ekonomi menengah ke atas. Keadaan ekonomi tokoh memengaruhi sikap tokoh dalam memercayai mitos. Dalam kutipan tersebut, tergambar tokoh Melisa yang tidak memercayai hal-hal mistis. Keadaan ekonomi yang mumpuni dengan ditunjang statusnya sebagai pelajar, menjadikan Melisa memiliki pola pikir yang realistis dan logis. Mitos menurutnya hanyalah bualan belaka.

\section{Tataran Sosiologis}

Tataran sosiologis merupakan tataran yang merujuk pada kehidupan sosial masyarakat pemilik mitos. Adapun yang termasuk ke dalam tataran sosiologis yaitu organisasi-organisasi sosial, hubungan anak dengan orang tua, perkawinan, dan hal-hal yang berkaitan dengan masalah sosial masyarakat pemilik mitos. Pada tataran sosiologis, ciri yang paling menonjol yang terdapat dalam novel Senjakala karangan Risa Saraswati adalah masyarakat yang digambarkan memiliki sifat religius yang tinggi. Hal tersebut dapat dibuktikan dengan taatnya para tokoh melaksanakan ibadah. Berikut 
kutipan yang menunjukkan hal tersebut.

Sekarang aku sudah paham, bukan tanpa sebab orangtua zaman dulu melarang anak-anak keluar rumah waktu senja. Pertama, mereka ingin agar anak-anak mereka berada di rumah untuk melaksanakan salat dan berdoa bersama keluarga, kedua... karena memang intensitas makhluk gaib sangat tinggi di jamjam tersebut. (hlm. 3)

Namun, tidak ada musola di sana, toilet umumpun tidak ada. Tanpa banyak berpikir, aku mulai bertayamum, lantas melaksanakan salat magrib di atas tanah, menghadap arah kiblat berdasarkan arah yang ditunjukkan telepon genggamku. (hlm. 133)

.... Namun, pukul enam sore bukan waktu yang aman, karena kedua orang tuanya pasti sedang bersembahyang. Sebentar lagi juga mereka akan menyerahkan lilin kepadanya agar dia juga bersembahyang. (hlm. 185)

Berdasarkan kutipan-kutipan di atas, terlihat ketaatan para tokoh dalam melaksanakan ibadah. Para tokoh digambarkan tidak pernah melewatkan waktu untuk beribadah sekalipun dalam keadaaan yang tak memungkinkan. Hal tersebut dapat terlihat pada kutipan halaman 133. Pada kutipan tersebut digambarkan tokoh yang hendak melaksankan salat magrib. Akan tetapi, dia tidak menemukan musala untuk melaksanakan ibadah, bahkan toilet untuk berwudu pun tidak ditemukannya. Dalam keadaan yang tak memungkinkan, dia tetap melaksanakan salat. Dia bertayamum dan melaksanakan salat di atas tanah.

Selain taatnya para tokoh dalam beribadah, ciri lain yang juga menunjukkan masyarakat memiliki sifat religius yang tinggi yaitu agama yang selalu menjadi dasar dalam setiap aspek kehidupan, seperti melakukan ibadah sebelum menjaga toko agar diberi keselamatan dan memohon perlindungan Tuhan saat memiliki masalah. Adapun kutipan yang menggambarkan hal tersebut yaitu sebagai berikut.

"Lis, nanti sebelum jaga kamu sembahyang dulu, ya! Inget, jangan sampai ketiduran. Meski sembahyang dulu pas jam enam, biar aman sampai tengah malam, sampai pagi lagi." Sang ibu berpesan, sambil membereskan beberapa helai pakaian anaknya yang baru saja beres dia setrika. (Hlm. 183)

Pada kutipan tersebut terdapat penggambaran bahwa agama yang dijadikan dalam kehidupan sehari-hari. Pada kutipan tersebut digambarkan bahwa dengan beribadah terlebih dahulu sebelum melakukan aktivitas tokoh merasa lebih aman. Tokoh merasa keselamatannya terjamin. Kutipan lain yang juga menunjukkan agama menjadi dasar dalam kehidupan sehari-hari adalah sebagai berikut.

"Kamu datang dalam doa Ibu, Gus. Saat Ibu salat malam. Suaramu terdengar jelas di telinga, kamu minta maaf dan diselamatkan oleh Ibu...." Tangis ibuku meledak. Dia memelukku erat. (hlm. 137)

Pada kutipan tersebut digambarkan tokoh ibu yang tidak percaya anaknya meninggal akibat kecelakaan. Kemudian, dia melakukan salat malam sebagai bentuk permohonan kepada Tuhan untuk diberikan petunjuk atas masalah yang menimpanya. Setelah salat malam, tokoh ibu berdoa. Dalam doanya, dia merasa bahwa anaknya 
datang meminta maaf dan minta diselamatkan. Tokoh ibu yang merasa itu sebagai petunjuk dari Tuhan, meyakini bahwa kematian anaknya sangat ganjil. Kematian anaknya bukan disebabkan oleh kecelakaan mobil seperti berita yang dia dengar.

\section{Tataran Kosmologis}

Tataran kosmologis merupakan tataran yang merujuk kepada kejadian di luar nalar manusia. Tataran kosmologis mencakup hal-hal gaib yang bersifat supranatural. Tataran kosmologis merupakan tataran yang mengacu pada peristiwa yang terjadi pada mitos yang dipercayai oleh masyarakat. Tataran kosmologis dalam novel Senjakala digambarkan dalam bentuk manusia yang kerap kali mendapatkan gangguan dari makhluk gaib pada saat pukul enam sore atau pada saat magrib tiba. Berikut akan dibahas mengeni tataran kosmologis yang terdapat dalam novel Senjakala karangan Risa Saraswati.

Sosok yang sekarang dia lihat di hadapannya masih sama dengan sosok tadi, seorang anak kecil berseragam dengan luka menganga di bagian kanan kepala, yang berlumuran darah. Anak kecil itu menyeringai, menatap dengan ekspresi seolah sedang menertawakan Jodi. Jodi tak bisa berkata apa-apa, bahkan tak mampu lagi meneteskan air mata karena ketakutan. (hlm. 80)

Belum habis rasa takutnya, tiba-tiba saja dia kembali menyaksikan pemandangan mengerikan. Dari arah lorong gelap menuju luar, sosok tinggi berambut panjang tadi kembali muncul, menertawakan Jodi yang kini mulai terkencing-kencing. Si anak kecil dengan luka menganga berlari mendekati sosok itu, lalu mereka tertawa berdua bagai kegirangan. (hlm. 80 )

Kutipan tersebut termasuk ke dalam tataran kosmologis yang ditandai dengan manusia yang diganggu oleh makhluk gaib. Tokoh Jodi digambarkan sedang bermain petak umpet bersama temanya di sekolah. Pada saat sedang mencari temannya yang bersembunyi, tokoh Jodi malah diganggu oleh hantu anak kecil dan sosok perempuan tinggi berambut panjang. Akibat gangguan dari makhluk tersebut, Jodi sampai terkencing-kencing hingga dia pingsan. Adapun sosok tinggi berambut panjang dalam masyarakat dikenal sebagai kuntilanak. Kutipan lain yang menunjukkan adanya tataran kosmologis yaitu sebagai berikut.

\footnotetext{
"Nah, itu alasannya! Besok aku akan mengunjungi pamanku di Tasik. Dia akan mencoba menyempurnakan almarhumah pasienku itu, agar tak keluyuran di rumah sakit dan tak menggangguku! Lagi pula, bukan hanya itu saja. Aku sering sekali diganggu hantu di rumah sakit ini. Aku sangat tersiksa!” (hlm. 94)

"Pokoknya, aku nggak berani jaga jam enam sampai tujuh malam. Apalagi di ruang isolasi! Brrr, seram! Tahu nggak, katanya, pada waktu-waktu seperti itu, hantu sedang agresif-agresifnya mengganggu manusia! Amit-amit ya Allah..." Ani berbicara lagi, kali ini memasang ekspresi ketakutan. (hlm. 94)
}

Pada kutipan tersebut tataran kosmologis ditunjukkan dengan tokoh yang kerap kali diganggu oleh makhluk gaib. Pada kutipan tersebut tokoh digambarkan merasa diikuti oleh pasiennya yang meninggal. Oleh karena itu, dia ingin pulang ke kampung halamannya untuk meminta pertolongan kepada pamannya guna menyempurnakan 
kematian pasiennya tersebut. Selain itu, tokoh tersebut kerap kali diganggu oleh hantu yang berada di rumah sakit. Akibat hal tersebut, dia tidak berani jika harus mendapatka giliran jaga pada pukul enam sampai tujuh malam. Hal tersebut disebabkan keyakinan si tokh bahwa pada jam-jam itu hantu memiliki intesitas yang tinggi untuk mengganggu manusia.

\section{KESIMPULAN}

Berdasarkan penelitian yang telah dilakukan, dapat disimpulkan bahwa hasil analisis pada tataran geografis menunjukkan penggambaran lokasi mitos dalam novel Senjakala kerap kali dilekatkan dengan sesuatu yang angker dan mistis. Tempat yang mistis dan angker merujuk pada aktivitas tokoh yang kerap kali diganggu oleh makhluk halus pada waktu matahari terbenam. Hasil analisis pada tataran techno-economic menunjukkan penggambaran ekonomi para tokoh dapat memengaruhi sikap tokoh dalam mempercayai mitos. Para tokoh yang memiliki taraf ekonomi yang baik cenderung memiliki tingkat pendidikan yang baik sehingga memengaruhi cara pandang tokoh dalam menyikapi mitos. Tokoh yang digambarkan memiliki ekonomi dan tingkat pendidikan yang baik cenderung tidak mempercayai peristiwa yang diyakini sebagai mitos. Hasil analisis pada tataran sosiologis menunjukkan masyarakat dalam novel Senjakala memiliki sifat religius yang tinggi. Para tokoh selalu mendasarkan diri pada agama dalam berbagai aspek kehidupannya, termasuk kaitannya dengan menghindarkan diri dari gangguan-gangguan makhluk halus. Hasil analisis tataran kosmologis menunjukkan para tokoh dalam novel Senjakala kerap kali diganggu oleh makhlukmakhluk halus pada pukul enam sore. Berdasarkan keempat tataran tersebut, mitos sandekala dalam novel Senjakala karangan Risa Saraswati ditunjukkan dengan adanya gangguan-gangguan dari makhluk halus yang kerap muncul pada waktu matahari terbenam.

\section{UCAPAN TERIMA KASIH}

Terima kasih kepada seluruh pihak yang berkenan diajak diskusi dan mendukung penelitian serta penulisan artikel ilmiah ini sehingga dapat dipublikasikan.

\section{REFERENSI}

Afsari, A.S., Septiani, A., \& Rismamelati, R. (2017). Pemertahanan Kepercayaan pada Masyarakat Talaga Majalengka dan Masyarakat Nagoya, Jepang. Jurnal Cendrasangkala, $\quad 3(2), \quad 1-12 . \quad$ doi: http://dx.doi.org/10.30870/candrasangkala.v3i2.3474

Ahimsa-Putra, H.S. (2012). Strukturalisme Lévi-Strauss Mitos dan Karya Sastra. Yogyakarta: Kepel Press.

Haviland, A.W. (1993). Antropologi. Jakarta: Erlangga.

Jamaluddin, M. (2003). Struktur Mitos dan Struktur Sosial Cerita Molowu dan Saweringadi. Kendari: Kantor Bahasa Provinsi Sulawesi Tenggara.

Kementerian Pendidikan dan Kebudayaan. (2018). Permendikbud Nomor 37 Tahun 2018 tentang Perubahan atas Permendikbud Nomor 24 Tahun 2016 tentang 
Kompetensi Inti dan Kompetensi Dasar Pelajaran pada Kurikulum 2013 pada Pendidikan Dasar dan Pendidikan Menengah. Jakarta: Kemendikbud.

Mustapa, H.H. (2010). Adat Istiadat Sunda. Bandung: Alumni.

Saraswati, R. (2018). Senjakala. Jakarta: Bukune.

Suhita, S., \& Purwahida, R. (2018). Apresiasi Sastra Indonesia dan Pembelajarannya. Bandung: Remaja Rosdakarya.

Peursen, C.A.V. (1988). Strategi Kebudayaan. Yogyakarta: Kanisius.

Purwahida, R. (2017). Interaksi sosial pada kumpulan cerpen Potongan Cerita di Kartu Pos karangan Agus Noor dan implikasinya terhadap pembelajaran sastra di SMA. Aksis: Jurnal Pendidikan Bahasa dan Sastra Indonesia 1(1). 118-134. doi: doi.org/10.21009/AKSIS.010107

Yuliyanti, D. (2017). Unsur cerita panji dalam Panji Kudan Narawangsa. Jurnal AKSIS: Jurnal Pendidikan Bahasa dan Sastra Indonesia, 1(1), 135-151. doi: https://doi.org/10.21009/10.21009/AKSIS.010108 